\title{
Solar photovoltaic panels significantly promote vegetation recovery by modifying the soil surface microhabitats in an arid sandy ecosystem
}

\author{
Yu Liu ${ }^{1,2}$ | Rui-Qi Zhang ${ }^{1}$ | Ze Huang ${ }^{1}$ Zhen Cheng ${ }^{1}$ | Manuel López-Vicente ${ }^{3}$ | Xiao-Rong Ma ${ }^{4}$ | \\ Gao-Lin $\mathrm{Wu}^{1,2,5}$ \\ ${ }^{1}$ State Key Laboratory of Soil Erosion and Dryland Farming on the Loess Plateau, Northwest A\&F University, Yangling, Shaanxi \\ 712100, PR China \\ ${ }^{2}$ Institute of Soil and Water Conservation, Chinese Academy of Sciences and Ministry of Water Resource, Yangling, Shaanxi 712100, \\ PR China \\ ${ }^{3}$ Department of Soil and Water, Experimental Station of Aula Dei (EEAD-CSIC), Zaragoza, Aragon 50059, Spain \\ ${ }^{4}$ Ningxia Baofeng Ecological Ranch Co., Ltd., Yingchuan, Ningxia 750001, PR China \\ ${ }^{5}$ CAS Center for Excellence in Quaternary Science and Global Change, Xi'an, Shaanxi 710061, PR China \\ Correspondence: G-L. Wu, State Key Laboratory of Soil Erosion and Dryland Farming on the Loess Plateau, Northwest A\&F \\ University, Yangling, Shaanxi 712100,PR China.Email: wugaolin@nwsuaf.edu.cn
}

Received: 5 April 2019 | Received in revised form: 12 June 2019| Accepted: 11 July 2019| Available online: 12 July 2019 at https://onlinelibrary.wiley.com/doi/abs/10.1002/ldr.3408 |

Land Degradation \& Development Volume 30, Issue 18, December 2019, pages 2177-2186. https://doi.org/10.1002/ldr.3408

\begin{abstract}
The arid sandy areas have great potential for producing solar power, and a large number of solar photovoltaic (PV) power (SPP) stations have been set-up in these regions across the world. Construction of SPP at large scale certainly changes the land surface with consequences on the local ecosystem. However, few studies have focused on these impacts. This study explored the influence of SPP on vegetation by modifying microhabitats. The soil water content (SWC), evaporation, photosynthetically active radiation (PAR), soil and air temperature (AT), vegetation coverage, biomass, and species richness were measured under different positions of the SPP and outside. The results showed that SWC in the station was much higher than that
\end{abstract}


observed outside the SPP, and the evaporation in the SPP was lower than outside $(\mathrm{P}<.05)$. The PAR below the PV panel line zone is much lower than the interval (IT) zone. The surface coverage, biomass, and species richness were significantly higher in the SPP than outside the IT zone and outside the SPP $(\mathrm{P}<.05)$. The AT under the panel was 1.67 times lower than above during the plant growing season. The microhabitat index has a high correlation with biomass, coverage, and species richness. PV panels could impact microhabitat in arid sandy areas and accelerate vegetation recovery progress and quality. The SPP construction would not only supply clean energy but also bring unintended ecological benefits in the future.

Keywords: Microhabitats; Photovoltaic panels; Sandy ecosystem; Soil water content; Vegetation recovery

\section{Introduction}

Fossil fuels, such as coal, oil, and natural gas, dominate worldwide electricity generation, as well as transportation, heating and industrial energy demands since 20th century. This dependence on fossil fuels deepends the impact of global warming and boosts the climate change risks. Compared to fossil fuels and other energy sources, such as nuclear power, renewable energy sources, such as solar and wind power, provide viable options for energy supply (MacDonald et al., 2016) because of their abundant provision and wide availability on earth (Barthelmie et al., 2014; Miller et al., 2014). Related to multiple climate benefits and sustainable development, renewable energy sources have been widely embraced as a primary solution to the current challenges of global energy demand, climate change, and environmental and societal sustainability (Dincer, 2000; Panwar et al., 2011). Solar energy is considered as one of the most promising alternatives due to its characteristics: inexhaustible, carbon-emission free, and non-generating liquid or solid waste products (Ito et al., 2003; Tsoutsos et al., 2005; Ahmed et al., 2011; Solangi et al., 2011). Solar energy generates electricity by using solar photovoltaic panels (SPP), and is grid-connected though photovoltaic (PV) power stations. The solar energy market has got extensive attention from worldwide governments. Updated to 2017, the total global PV installed capacity already reached 404.5 gigawatts (GW), nearly 225 times higher than the capacity in 2000 (1.8 GW). In 2017, China had installed 53.3\% of the world's solar capacity, with an increase of $52.8 \mathrm{GW}$ with respect to its capacity in 2016. The United States was the world's second largest PV market, and increased 10.6 GW compared to its capacity in 2017. In the same year, Japan hold $12.2 \%$ of the global share while Germany took up to $10.6 \%$ (Europe Solar Power, 2018). Thus, PV industry has become a fast-growing industry that has gradually developed a huge market worldwide. 
The PV installed capacity of Africa and the Middle East region has also developed very strongly due to their high solar radiation potential. The regional radiation potential values are the most significant data for locating the solar power stations (Janke et al., 2010; Sánchez-Lozano et al., 2013; Jahangiri et al., 2016). Other semi-arid and arid areas of the world, like Nevada (USA), Baja California (Mexico), Atacama (Chile), Southern Spain (OECD-Europe), Empty Quarter (Arabian Peninsula), Gobi (China, Russia), Rajasthan (India), Sahara (North Africa), Kalahari (South Africa), and Great Victoria, Gibson, and Tanami (Australia), have a great potential for installing large scale PV power stations due to the combined conditions of a large amount of available land, and areas with high air optical quality (Muneer et al., 2003; Ito et al., 2003).

In the latest years, the Chinese government has prompted a great deal of efforts to maintain and develop the solar industry. The solar recourses are unevenly distributed throughout China, which decrease from northwest to southeast. The Provinces located in the northwestern part, like Xizang, Qinghai, Gansu, Xingjiang, and Ningxia concentrate most of the solar energy, and thus are considered as the future energy base of China (Wu et al., 2014). Due to the low density of solar energy in nature, and the current transfer efficiency of the SPP (Ito et al., 2003), the solar PV stations need a large land area to install photovoltaic panels. Compared to the densely populated and land-scary east part of China, the northwest region of the country is highly suited to install solar electric stations; when considering both land use efficiency and solar energy distribution. Nonetheless, most part of these regions are plateauing and/or desert, such as the Gobi and the steppes, which have the most sensitive and formidable ecological environments in the whole state (Du et al., 2019). SPP's construction would cause significant soil surface disturbances that increase the risk of land degradation of the fragile arid ecosystem.

Some studies have evaluated the environmental impacts of the SPPs during their lifecycle, including metrics about the energy payback time (EPBT), and Greenhouse Gases (GHG) emissions (Northrup et al., 2012). Emissions' reduction and health benefits brought by the SPP's establishment are not open to question (Hosenuzzaman et al., 2015). Visual impacts, air pollution, and natural resources depletion associated to the installation of SPP were also evaluated (Tsoutsos et al., 2005). Some researchers have mentioned that SPP could impact and modify landscape during their construction through activities, such as earth movement and by equipment and facilities transportation (Tsoutsos et al., 2005, Hernandez et al., 2015a). Besides, Wu et al. (2014) reported that large-scale concentrated solar power plants in northwest China had huge and positive impacts on the local environment, especially in alleviating soil erosion. The ecological impacts of SPP are often assumed to be negligible, and thus there are few studies in the literature that investigate the influence of 
SPP's establishment on the local ecosystem. Besides, many of these effects are hypothesized with little peer-reviewed evidences (Northrup and Wittemyer, 2012). Li et al. (2018) used a climate mode with dynamic vegetation to estimate the unintended climate consequences leaded by large-scale installations of wind and solar farms. These authors indicated that the effects of large-scale solar farms are consistently conducted with significant locally, and further studies are required to assess the impacts of smaller solar farms installed at specific locations (Li et al., 2018). Nevertheless, the environmental and ecological impacts of SPP are still unresolved questions. The previous available studies about PV stations have not dealt in detail with the impacts on both the local environment and the ecology.

This study aims to evaluate both the environmental and the ecological effects of SPP installed in an arid and sandy landscape of central China. The photovoltaic power station located in Yinchuan city was chosen for this study because it is located on the border of the Mu Us desert. This is a transitional region and is highly sensitive to human activities, such as land use changes (Cao et al., 2015), and natural factors (Liang et al., 2016). The main contribution of this study is the quantification of the effects of the SPP's establishment on the soil water content (SWC), evaporation, soil and air temperature, surface coverage, biomass, and species richness. The results of this study will enable to ascertain the ecological significance of SPP in arid and sandy regions.

\section{Materials and methods}

\subsection{Study sites}

This study was carried out in the SPP $\left(38^{\circ} 31^{\prime} 57^{\prime \prime} \mathrm{N}, 106^{\circ} 36^{\prime} 47^{\prime \prime} \mathrm{E} ; 1222 \mathrm{~m}\right.$ a.s.l.) constructed near Yinchuan City, at Xingqing district. This area is located in the southwest border of the Mu Us Desert, in the Ningxia Hui Autonomous Region, China. The study area is part of the wind erosion zone, and it has a moderate temperate continental monsoon climate. The average annual precipitation is ca. $200 \mathrm{~mm}$, and the annual evaporation is approximately $2250 \mathrm{~mm}$. The mean annual temperature is $8.4^{\circ} \mathrm{C}$. The annual hours of sunshine are $3075.5 \mathrm{~h}$, and the mean annual frost-free period is approximately 160 days. The soil type is light sierozem. Natural vegetation is scarce without presence of forest. Dominant plant species in this area are mainly psammophytic shrubs, and herbaceous plants, including Halogeton arachnoideus, Artemisia scoparia, Artemisia ordosica, and Artemisia sphaerocephala. All the experiments were conducted in the Baofeng solar photovoltaic power station, which was constructed in 2016. This station occupies an area of about $15.33 \mathrm{~km}^{2}$ and has an installed capacity of 640 megawatts (MW). 


\subsection{Field experiments}

The SPP were constructed with a $7 \mathrm{~m}$ line distance in the East-West direction, and $6.8 \mathrm{~m}$ in the South-North direction. The SPP were installed at $2.15 \mathrm{~m}$ above the ground, and the installation angle is controlled by an automatic optical tracking system. We defined three zones in this study (Fig. 1d). The land ground which is vertically below the SPP was defined as the shadow zone (S zone); and the land surface between two S zones was defined as the non-shadow zone (NS zone). The land ground that is outside and next to the station was defined as the OS zone. Microhabitats indicators like soil moisture, surface temperature (ST), evaporation, and photosynthetically active radiation (PAR) were measured in each zone. The air temperature (AT) above and below the SPP was monitoring by temperature sensors throughout the year. An intensive field study was conducted to examine the aboveground biomass, vegetation coverage, and plant species in the three zones. All soil and plant samples were collected from July 23 to 27, 2018.

\subsection{Sampling and measurements}

A dual-range digital thermometer (OS542, OMEGA, USA) was used to measure the ST at every point. ST was measured three times every $2 \mathrm{hr}$ from 10:00 a.m. to 6:00 p.m. at each point (same location). The position to measure ST is randomly selected at each point about 5-cm height above the ground. The ST of each zone is the average value of 5 points in $6 \mathrm{hr}$. PAR was also measured three times every $2 \mathrm{hr}$ from 10:00 a.m. to 6:00 p.m. at each point (same location). PAR was measured randomly by a canopy effective radiation recorder (ECA-GG01, Beijing ECOA Company, China) under the vegetation canopy $(10 \mathrm{~cm}$ above the ground) in the three zones. The average value in $6 \mathrm{hr}$ of 5 points for each zone stands for the PAR of the three zones.

The AT above (10 $\mathrm{cm}$ above the panel) and under (100 $\mathrm{cm}$ above the ground) the PV panels were monitored with a temperature sensor (S-THB-M002, HOBO, USA) from August 2017 to July 2018. The sensor reads the AT every 5 min. After outliers rejection, we group the AT value in $24 \mathrm{hr}$ day -1 and use the daily mean temperature to calculate monthly mean AT. Temperature variation is observed in July 2018. Temperature variation is the difference value of AT above panel and under the panel in $24 \mathrm{hr}$ (the average AT value in $24 \mathrm{hr}$ of July 2018).

Three culture dishes (internal diameter of $150 \mathrm{~mm}$ ) were utilized as evaporation pan to measure the evaporation of two consecutive days at each point: July 24 and 25 . The position of dishes is randomly 
selected at each point. The culture dishes were filled with water and weighed twice: just before installing and then $24 \mathrm{hr}$ later. The evaporation capacity (EC; $\mathrm{mm}$ ) was calculated as follows:

$$
E C=\left(W_{1}-W_{2}\right) \rho_{w} / S_{b}
$$

where $\boldsymbol{W}_{2}(\mathrm{~g})$ is the weight of the dish with the remaining water after $24 \mathrm{hr}, \boldsymbol{W}_{\boldsymbol{I}}(\mathrm{g})$ is the weight of the dish with the water when it was settled, $\boldsymbol{\rho}_{w}$ is $1 \mathrm{~g} \mathrm{~cm}^{-3}$, and $\boldsymbol{S}_{\boldsymbol{b}}$ is the base area of the standard small evaporation pan $(\mathrm{r}=10 \mathrm{~cm})$.

The gravimetric SWC (\%) of the 0- to $100-\mathrm{cm}$ soil depth range was measured every $10-\mathrm{cm}$ soil layer by a $4-\mathrm{cm}$ diameter and $20-\mathrm{cm}$ height soil auger at each point. Soil samples were collected in a $1.0 \mathrm{~m} \times 1.0 \mathrm{~m}$ quadrat at each point. A total of 150 soil samples were taken in the three zones. The soil samples were stored in aluminum specimen boxes and weighed immediately after collection (using an electronic balance) and then weighed again after the samples were dried at $105{ }^{\circ} \mathrm{C}$ for $24 \mathrm{hr}$. The SWC of each soil layer was calculated as follows:

$$
S W C_{i}=\left(m_{i 1}-m_{i 2}\right) / m_{2} \cdot 100 \%
$$

where $\boldsymbol{m}_{\boldsymbol{I}}(\mathrm{g})$ is the soil sample weight after collection, and $\boldsymbol{m}_{2}(\mathrm{~g})$ is the weight of the dried soil samples. $\boldsymbol{i}$ is the number of the soil layer, $\boldsymbol{i}=1,2,3, \ldots, 10$.

Mean $S W C$ of 0-100 cm (\%) was calculated below:

$$
S W C=\left(S W C_{1}+S W C_{2}+S W C_{3}+\ldots+S W C_{10}\right) / 10
$$

Plant coverage and species richness were estimated by using five quadrats of $1.0 \mathrm{~m} \times 1.0 \mathrm{~m}$. The position of quadrats was randomly selected in each point. All the aboveground plant parts were collected and dried at $75{ }^{\circ} \mathrm{C}$ for $72 \mathrm{hr}$ in each quadrat, and then the dry mass in each quadrat was weighed. The average value of the dry mass represents the biomass of vegetation in the three zones. The number of species and vegetation coverage was estimated at each quadrat, and the species richness and vegetation coverage of each zone were calculated as the mean value of species number and vegetation coverage obtained in the five quadrats.

\subsection{Data preprocessing and statistical analyses}

All data preprocessing was performed using Excel 2013 worksheet software (Microsoft Office Suite, USA). The One-way ANOVA (analysis of variance), Pearson correlation analysis, and the tests of significance were conducted by using SPSS 22.0 software (IBM, Montauk, New York, USA). Significant differences were determined at a significance level of 0.05 . The figures were plotted by using SigmaPlot 12.5 software (Systat Software Inc., San Jose, CA, USA), and the table were produced with Excel 2016. 


\section{Results}

\subsection{Effects of Solar PV Panels on surface microhabitats}

The results showed clear differences in the soil water content (SWC), evaporation, soil temperature (ST), and photosynthetically active radiation (PAR) between the S, NS, and OS zones. On the other hand, SWC decreased with increasing the soil depth, up to $100 \mathrm{~cm}$, describing the same spatial pattern in the three zones (Fig. 2a). SWC in the OS zone was always lower than the values in the S and NS zones considering the 100 $\mathrm{cm}$ soil layer. There were no significant differences of ST between the three zones (Fig. 2c). ST of the highest NS zone was only $0.45^{\circ} \mathrm{C}$ higher than the value in the lowest $\mathrm{S}$ zone. The evaporation and PAR of three zones were significantly different among them (Fig. 2b, 2d). The evaporation in the OS (E-OS) zone was significantly higher than that in the other two zones of the solar station $(\mathrm{P}<0.05)$. E-OS was 2.05 and 1.55 times higher than the values obtained in the S and NS zones, respectively; while inside the solar station the evaporation of the NS zone was $32 \%$ higher than evaporation in the S zone. With regard to PAR, the order of three zones, from the highest to the lowest values, was: OS $>$ NS $>S$. The PAR of $S$ zone was significantly lower than that in the other two zones $(\mathrm{P}<0.05): 56.9 \%$ and $67.4 \%$ lower than in the NS and OS zones, respectively. There was no significant difference between the PAR in the NS and OS zones.

The monthly average air temperature (AT) above the SPP mirrored the trend of the AT under the panels: in both cases, AT started rising on February and reached the peak values in July (Fig. 3a). Between September and November, the AT above SPP was always lower than under the panels. During the remaining nine months, the average AT above SPP were higher than under the panels. During the plant's growing season (from April to August), the average AT above the panels was $36.21^{\circ} \mathrm{C}$, whereas under the panels the average temperature was only of $21.78^{\circ} \mathrm{C}$. AT above SPP was approximately 1.67 times higher than that under the panels during the growing seasons. This temperature variation also changed within a day (Fig. 3b). From 12 PM to 18 PM, SPP strongly reduced the temperature. During these six hours, the temperature variation was above the mean temperature variation estimated for the 24 hour-period that was of $19.27^{\circ} \mathrm{C}$.

\subsection{Effects of Solar PV Panels on vegetation recovery}

The biomass and surface coverage in the S and NS zones were higher than the values in the OS zone (Fig. 4a, 4b). The biomass of the S and NS zones was 30 and 15.4 times higher than that in the OS zone, while the surface coverage was 6.8 and 6.2 times higher than in the OS zone, respectively $(\mathrm{P}<0.05)$. Inside the solar 
station, the S and NS zones did not have significant differences in the coverage; whereas the biomass in the $\mathrm{S}$ zone was nearly two times higher than in the NS zone $(\mathrm{P}<0.05)$. The species richness of the three zones showed clear differences between the areas inside and outside the solar station (Fig. 4c). The NS zone presented the highest species richness (5.5), the S zone showed intermediate values (4.5), and the OS zone had the lowest values (2.6). There was no significant difference between the two zones inside the station, although both zones had higher species richness than the value estimated in the OS zone $(\mathrm{P}<0.05)$.

\subsection{The correlation between microclimate and vegetation}

The results of correlation analysis for the environmental and vegetation indices are set out in Table 1. A positive correlation was found between evaporation and PAR, whereas evaporation was negatively correlated with the soil water storage ( $W$ in Eq. (3)). A negative correlation was also observed between evaporation and the vegetation indices. $W$ was positively correlated with the vegetation coverage, and biomass. Besides, $W$ and species richness had a significant correlation between them. Moreover, the vegetation indices like the coverage, biomass, and species richness were negatively correlated with ST and PAR.

\section{Discussion}

Large-scale SPP have been mainly installed in the areas that have minimal competition for land surface against natural and other human land uses, for instance where landscapes such as deserts, the Gobi and steppes (Hernandez et al., 2015b). These regions are sensitive to environment changes where soil erosion might be intensified and sandstorm probability could be increased due to land use changes. Multiple environment impacts may change a lot during the SPP's life-cycle, especially during the construction stage. Our study has proved the existence of environmental and ecological changes influenced by SPP. The panels created a heterogeneous radiation environment and covered ground owing to the fluctuant shading, and thus leading a changing energy cycle (Cossu et al., 2014). The changing of the energy cycle led to the variation of the microhabitat's characteristics, such as the soil temperature, wind speed, precipitation, and radiation. Previous studies have shown that PV panels of large-scale solar farms in the Sahara directly reduced the surface albedo, creating a positive albedo-precipitation-vegetation feedback, which triggered an increasing temperature and precipitation (Li et al., 2018). At a smaller scale, this study has showed that the presence of SPP changed the microhabitats factors in different ways. SPP convert the solar radiation into electricity energy (Lewis et al., 2006), according to the Law of Conservation of Energy, and the land surface under the 
power station would receive less radiation than the uncover land (Zhou et al., 2012). Hence, the PAR in the station was significantly lower than the PAR outside the station, especially in the S zone. ST changed in a quite different way due to the influence of the SPP, and we did not observed significant differences between the three zones (Fig. 2c). However, the air temperature (AT) under the panels differed from the AT above the SPP. AT under the panels was suitable for plants during their growing season. A likely explanation is that the radiative balance was modified by the panel shelter, which provided an open structure with sufficient air circulation (Marrou et al., 2013a). Besides, the panels directly decrease the transfer of solar energy to heat energy though shading.

The water cycle was also influenced by the SPP. The soil water content (SWS) in the power station was higher than in the area outside the station, while evaporation just showed the opposite trend. From one side, the panels intercepted part of the precipitation; from the other side, the panels' inclination modified the spatial distribution of the rainfall that reached the soil surface after being temporally stored in the panels (Armstrong et al., 2014). Thus, SWS in the NS zone was slightly higher than in the S zone (Fig. 2a). The shading effect of the panels explained the significantly lower evaporation that was observed in the station (Fig. 2b). These results agreed with the study of Marrou et al. (2013b) who found that the shadow of the panels could save up to $14-29 \%$ of evapotranspired water in vegetable crops. Furthermore, the shading effects can increase the sensible heat flux of the ground layer, encouraging a decrease of the latent heat flux and soil heat flux, and thus limiting evaporation (Coutts et al., 2013). All these effects caused the observed heterogeneity of SWC distribution inside and outside the station. SPP are usually located in areas with a lack of water that suffer high potential evaporation. Under the context of global warming and water resource shortage, the effects of panels that could maintain a relatively higher SWC and lower evaporation would leaving more water for plant, and thus facilitate the recovery or improvement of the vegetation destroyed during the solar station construction. These benefits provide a consistent advantage in the near future.

The mean vegetation fractional coverage in middle Asia, where northwestern China is included, ranges from 3\% to 33\% (Zhang et al., 2016). In our study, we found that the vegetation coverage of the OS zone was $13.4 \%$, just among the average level of coverage. However, the vegetation coverage in the solar station area was over $85 \%$, and in the $\mathrm{S}$ zone reached up to $93.5 \%$, which is a value much higher than the average level of vegetation coverage at regional scale. At the same time, the biomass and species richness were significantly higher in the solar station than in the area outside the station. The construction of SPP destroyed the natural vegetation, and after two years (2016-2018) of recovery, significant differences in vegetation 
characteristics had already shown. The vegetation below the SPP had shown a better recovery in terms of quality and speed.

This study has proven that SPP have modified the microhabitats, especially in gathering precipitation, alleviating evaporation, and adjusting both the soil and air temperature. Plants grow in arid areas are highly affected by both temperature (Beedlow et al., 2013) and water availability (Zhou et al., 2011). SWC has a high correlation with vegetation coverage, and species richness. When vegetation is facing prolonged drought stress, SWC would strongly control the spatiotemporal patterns of biomass (Kammann et al., 2011). In water-limited areas, water is the foundation of vegetation planting (Kammann et al., 2017). Besides, good water conditions have positive effects on juvenile crop stages, which is vital to vegetation establishment (Marrou et al., 2013a). This study has indicated that SPP can provide a better water conditions for plant growth in arid sandy ecosystems.

Plants in arid sandy areas always face heat stress conditions and in most cases leaves are dried during the growing season. High temperatures could cause serious physiological injuries to plants, such as scorching of leaves and stems, leaf abscission, and senescence. Besides, high temperatures could affect the shoot net assimilation rates that reduces the plant growth, which consequently lead to a decrease in the total dry weight of the plant (Bita and Gerats, 2013). The results of this study showed that SPP could effectively reduce the temperature during both the growing season, and in the hottest time of the day. SPP could let plants alleviate heat stress, and prevent plant productivity decrease. Moreover, in a dual-purposed system that should like produce food (crops, e.g. lettuces) and electricity at the same time, our study showed that plants can maintain a high yield in the area under the shadow of the SPP. We also found that high biomass can be achieved under reduced lighting conditions. Light reduction is not necessarily detrimental to crop production (Dupraz et al., 2011). Thus, SPP favored the development of a microhabitat with lower evaporation and higher SWC, which enabled vegetation development with high coverage, biomass, and biodiversity.

Prior studies focused on dryland and desert ecosystems have noted the importance of vegetation coverage and biomass to provide important ecological services such as soil protection and animal feeding (Jiang et al., 2017). Soil erosion process is influenced by natural and human factors, and thus it has close-fitting connection with climate conditions, such as precipitation and temperature, ground cover (e.g. vegetation cover) and land uses (Alexander et al., 2017; Li et al., 2017; Wei et al., 2017). Vegetation cover has a lower and an upper threshold for controlling wind erosion. A plant coverage lower than $10 \%$ has little ability to reduce wind velocity at the soil surface, while the effect of vegetation on reducing wind erosion has 
basically reached the maximum when plant cover is ca. $40 \%$ or above (Jiang et al., 2017). The average coverage in the PV power station was $90.5 \%$, and the solar photovoltaic panels covered more land, modifying the land surface properties, in particular, increasing the surface roughness. Moreover, the higher biomass in the station could let more litter get into the soil, which provides nutrition, and improve the soil structure (Jia et al., 2018a; 2018b) that enhances the soil water holding capacity. Meanwhile, the observed better soil water conditions could provide a better scenario for the plant growth, higher biomass production and total coverage. These changes created a positive vegetation-environment feedback associated to the solar PV station. Altogether, these results reflected that the establishment of SPP enhances the resistance capacity of an area against wind erosion, and has positive ecological effects under adverse climatic conditions. SPP's installation in arid sandy areas could provide not only electricity energy but also huge ecological benefits, which could help other researchers and policy-makers to pay more attention to the environmental benefits besides the economic profits. Our study was just a primary research of the solar photovoltaic panel's ecology effects, and further studies will be needed in more sites to gather large datasets that can support sound conclusions.

\section{Conclusions}

SPP in arid areas could perpetuate the efficient use of regional solar recourses and bring both economic and ecological benefits. SPP installation had a big influence on the surface microhabitat in the arid sandy ecosystem of Western China. Higher SWC and lower evaporation constitute better water conditions, which were the key factors of improving the ecological environment in the sandy areas. Moreover, the PV panels could relieve heat stress by adjusting the air and ground temperature during the plants' growing season. This hydrological process and the modified temperature conditions supported the plant growth and thus accelerated vegetation recovery. After 2 years (2016-2018) of recovery, vegetation coverage in the station reached a very high value $(90.5 \%)$, which could provide effective protection to soil against wind erosion. Furthermore, biomass and species diversity increased owing to the combined influences of the PV panels. Therefore, PV panels made the surface microhabitats different to some extent, and positive vegetation-microhabitat feedback thus could promote the ecological restoration in the arid sandy region.

\section{Acknowledgements}

This study was funded by the project of the National Natural Science Foundation of China (NSFC 41722107), the Light 
of West China Program of the Chinese Academy of Sciences (XAB2015A04 and XAB2018B09), and the Youth Talent Plan Foundation of the Northwest A\&F University (2452018025). We thank the editor and anonymous reviewers for their constructive comments and suggestions on this manuscript.

\section{References}

Ahmed, F., Al Amin, A. Q., Hasanuzzaman, M., Saidur, R., 2013. Alternative energy resources in Bangladesh and future prospect. Renew. Sust. Energy Rev. 25, 698-707.

Armstrong, A., Waldron, S., Whitaker, J., Ostle, N. J., 2014. Wind farm and solar park effects on plant-soil carbon cycling: uncertain impacts of changes in ground-level microclimate. Global Change Bio. 20, 1699-1706.

Alexander, J.K., Philip, N.O., Ellen, L.P., David, A.L., 2017. The role of soil surface properties on the particle size and carbon selectivity of interrill erosion in agricultural landscapes. Catena 153, 194-206

Barthelmie, R. J., Pryor, S. C., 2014. Potential contribution of wind energy to climate change mitigation. Nat. Clim. Change 4, 684.

Beedlow, P. A., Lee, E. H., Tingey, D. T., Waschmann, R. S., Burdick, C. A., 2013. The importance of seasonal temperature and moisture patterns on growth of Douglas-fir in western Oregon, USA. Agr. Forest Meteor. 169, 174-185.

Bita, C., Gerats, T., 2013. Plant tolerance to high temperature in a changing environment: scientific fundamentals and production of heat stress-tolerant crops. Front. Plant Sci. 4, 273.

Cao, Q., Yu, D., Georgescu, M., Han, Z., Wu, J., 2015. Impacts of land use and land cover change on regional climate: A case study in the agro-pastoral transitional zone of China. Environ. Res. Lett. 10, 124025.

Coutts, A. M., Daly, E., Beringer, J., Tapper, N. J., 2013. Assessing practical measures to reduce urban heat: Green and cool roofs. Build. Environ. 70, 266-276.

Cossu, M., Murgia, L., Ledda, L., Deligios, P. A., Sirigu, A., Chessa, F., Pazzona, A., 2014. Solar radiation distribution inside a greenhouse with south-oriented photovoltaic roofs and effects on crop productivity. Appl. Energ. 133, 89-100

Dincer, I. 2000. Renewable energy and sustainable development: a crucial review. Renew. Sust. Energy Rev. $4,157-175$

Du, H., Zuo, X., Li, S., Wang, T., Xue, X., 2019. Wind erosion changes induced by different grazing 
intensities in the desert steppe, Northern China. Agr. Ecosyst. Environ. 274, 1-13.

Dupraz, C., Marrou, H., Talbot, G., Dufour, L., Nogier, A., Ferard, Y., 2011. Combining solar photovoltaic panels and food crops for optimising land use: towards new agrivoltaic schemes. Renew. Energ. 36, $2725-2732$.

Europe, S., 2018. Global Market Outlook for Solar Power 2018-2022. SolarPower Europe: Brussels, Belgium.

Hernandez, R. R., Hoffacker, M. K., Murphy-Mariscal, M. L., Wu, G. C., Allen, M. F., 2015a. Solar energy development impacts on land cover change and protected areas. PNAS. 112, 13579-13584.

Hernandez, R. R., Hoffacker, M. K., Field, C. B., 2015b. Efficient use of land to meet sustainable energy needs. Nat. Clim. Change 5, 353.

Hosenuzzaman, M., Rahim, N. A., Selvaraj, J., Hasanuzzaman, M., Malek, A. A., Nahar, A., 2015. Global prospects, progress, policies, and environmental impact of solar photovoltaic power generation., Renew. Sust. Energy Rev. 41, 284-297.

Ito, M., Kato, K., Sugihara, H., Kichimi, T., Song, J., Kurokawa, K., 2003. A preliminary study on potential for very large-scale photovoltaic power generation (VLS-PV) system in the Gobi desert from economic and environmental viewpoints. Sol. Energ. Mat. Sol. C. 75, 507-517.

Janke, J. R., 2010. Multicriteria GIS modeling of wind and solar farms in Colorado. Renew. Energ. 35, 2228-2234.

Jahangiri, M., Ghaderi, R., Haghani, A., Nematollahi, O., 2016. Finding the best locations for establishment of solar-wind power stations in Middle-East using GIS: A review. Renew. Sust. Energy Rev. 66, 38-52.

Jia, C., Liu, Y., He, H., Miao, H. T., Huang, Z., Zheng, J., Han, F., Wu, G. L., 2018a. Formation of litter crusts and its multifunctional ecological effects in a desert ecosystem. Ecosphere 9, e02196.

Jia, C., Huang, Z., Miao, H. T., Lu, R., Li, J., Liu, Y., Wu, G. L., 2018b. Litter crusts promote herb species formation by improving surface microhabitats in a desert ecosystem. Catena 171, 245-250.

Jiang, C., Liu, J., Zhang, H., Zhang, Z., Wang, D., 2019. China's progress towards sustainable land degradation control: Insights from the northwest arid regions. Ecol. Eng. 127, 75-87.

Kammann, C. I., Linsel, S., Gößling, J. W., Koyro, H. W., 2011. Influence of biochar on drought tolerance of Chenopodium quinoa Willd and on soil-plant relations. Plant Soil 345, 195-210.

Lewis, N. S., Nocera, D. G., 2006. Powering the planet: Chemical challenges in solar energy utilization. PNAS. 103, 15729-15735. 
Li, Y., Kalnay, E., Motesharrei, S., Rivas, J., Kucharski, F., Kirk-Davidoff, D., Bach, E., Zeng, N., 2018. Climate model shows large-scale wind and solar farms in the Sahara increase rain and vegetation. Science 361, 1019-1022.

Li, Z., Liu, C., Dong, Y., Chang, X., Nie, X., Liu, L., Xiao, H., Lu, Y., Zeng, G., 2017. Response of soil organic carbon and nitrogen stocks to soil erosion and land use types in the Loess hilly-gully region of China. Soil Tillage Res. 166, 1-9.

Liang, P., Yang, X., 2016. Landscape spatial patterns in the Maowusu (Mu Us) Sandy Land, northern China and their impact factors. Catena 145, 321-333.

MacDonald, A. E., Clack, C. T., Alexander, A., Dunbar, A., Wilczak, J., Xie, Y., 2016. Future cost-competitive electricity systems and their impact on US CO2 emissions. Nat. Clim. Change 6, 526.

Marrou, H., Guilioni, L., Dufour, L., Dupraz, C., Wery, J., 2013a. Microclimate under agrivoltaic systems: is crop growth rate affected in the partial shade of solar panels? Agr. Forest Meteor. 177, 117-132.

Marrou, H., Dufour, L., Wery, J., 2013b. How does a shelter of solar panels influence water flows in a soil-crop system?. Eur. J. Agron. 50, 38-51.

Miller, L. M., Gans, F., Kleidon, A., 2011. Estimating maximum global land surface wind power extractability and associated climatic consequences. Earth Syst. Dynam. 2, 1-12.

Muneer, T., Asif, M., Kubie, J., 2003. Generation and transmission prospects for solar electricity: UK and global markets. Energ. Convers Manage. 44, 35-52.

Northrup J.M., Wittemyer G., 2012. Characterising the impacts of emerging energy development on wildlife, with an eye towards mitigation. Ecol. Lett. 16. 112-125.

Panwar, N. L., Kaushik, S. C., Kothari, S., 2011. Role of renewable energy sources in environmental protection: A review. Renew. Sust. Energy Rev. 15, 1513-1524.

Sampaio, P. G. V., González, M. O. A., 2017. Photovoltaic solar energy: Conceptual framework. Renew. Sust. Energy Rev. 4, 590-601.

Sánchez-Lozano, J. M., Teruel-Solano, J., Soto-Elvira, P. L., García-Cascales, M. S., 2013. Geographical Information Systems (GIS) and Multi-Criteria Decision Making (MCDM) methods for the evaluation of solar farms locations: Case study in south-eastern Spain. Renew. Sust. Energy Rev. 24, 544-556.

Solangi, K. H., Islam, M. R., Saidur, R., Rahim, N. A., Fayaz, H., 2011. A review on global solar energy policy. Renew. Sust. Energy Rev. 15, 2149-2163.

Tsoutsos, T., Frantzeskaki, N., Gekas, V., 2005. Environmental impacts from the solar energy technologies. 
Energy Policy 33, 289-296.

Wei, S., Zhang, X., McLaughlin, N. B., Chen, X., Jia, S., Liang, A., 2017. Impact of soil water erosion processes on catchment export of soil aggregates and associated SOC. Geoderma 294, 63-69.

Wu, Z., Hou, A., Chang, C., Huang, X., Shi, D., Wang, Z., 2014. Environmental impacts of large-scale CSP plants in northwestern China. Environ. Sci. Proc. Impacts 16, 2432-2441.

Zhang, C., Lu, D., Chen, X., Zhang, Y., Maisupova, B., Tao, Y., 2016. The spatiotemporal patterns of vegetation coverage and biomass of the temperate deserts in Central Asia and their relationships with climate controls. Remote Sens. Environ. 175, 271-281.

Zhao, Y.L., Wang, Y.Q., Wang, L., Fu, Z.H., Zhang, X.Y., Cui, B.L., 2017. Soil-water storage to a depth of 5 $\mathrm{m}$ along a 500-km transect on the Chinese Loess Plateau. Catena 150, 71-78.

Zhou, L., Tian, Y., Roy, S. B., Thorncroft, C., Bosart, L. F., Hu, Y., 2012. Impacts of wind farms on land surface temperature. Nat. Clim. Change 2, 539.

Zhou, X., Zhang, Y., Ji, X., Downing, A., Serpe, M., 2011. Combined effects of nitrogen deposition and water stress on growth and physiological responses of two annual desert plants in northwestern China. Environ. Exp. Bot. 74, 1-8.

Table 1 Pearson correlations between the microhabitats and vegetation indices.

\begin{tabular}{cccccccc}
\hline Variation & $\begin{array}{c}\text { ST } \\
\left({ }^{\circ} \mathrm{C}\right)\end{array}$ & $\begin{array}{c}\text { Evaporation } \\
(\mathrm{mg})\end{array}$ & $\begin{array}{c}\text { PAR } \\
\left(\mu \text { mouls }^{-1} \mathrm{~m}^{-2}\right)\end{array}$ & $\begin{array}{c}\text { SWC } \\
(\mathrm{mm})\end{array}$ & $\begin{array}{c}\text { Coverage } \\
(\mathrm{mm})\end{array}$ & $\begin{array}{c}\text { Biomass } \\
\left(\mathrm{g} \mathrm{m}^{-2}\right)\end{array}$ & $\begin{array}{c}\text { Species } \\
\text { richness }\end{array}$ \\
\hline ST & 1.00 & 0.64 & 0.88 & -0.07 & -0.44 & -0.79 & -0.04 \\
Evaporation & & 1.00 & 0.93 & -0.81 & -0.97 & -0.97 & -0.80 \\
PAR & & & 1.00 & -0.53 & -0.82 & -0.99 & -0.51 \\
W & & & & 1.00 & 0.93 & 0.66 & $1.00^{*}$ \\
Coverage & & & & & 1.00 & 0.90 & 0.92 \\
Biomass & & & & & & 1.00 & 0.64 \\
\hline
\end{tabular}

Note: Microhabitats indices: soil temperature (ST), evaporation, photosynthetically active radiation (PAR), soil water storage ( $W$ in Eq. (3)). Vegetation indices: Coverage, Biomass, and Species richness. * Correlation is significant at the 0.05 level. 


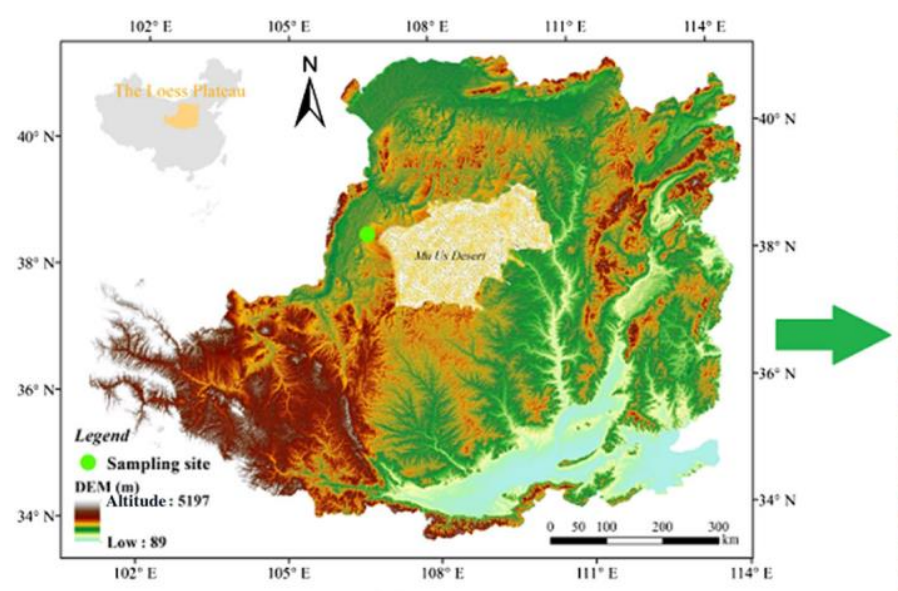

(a)

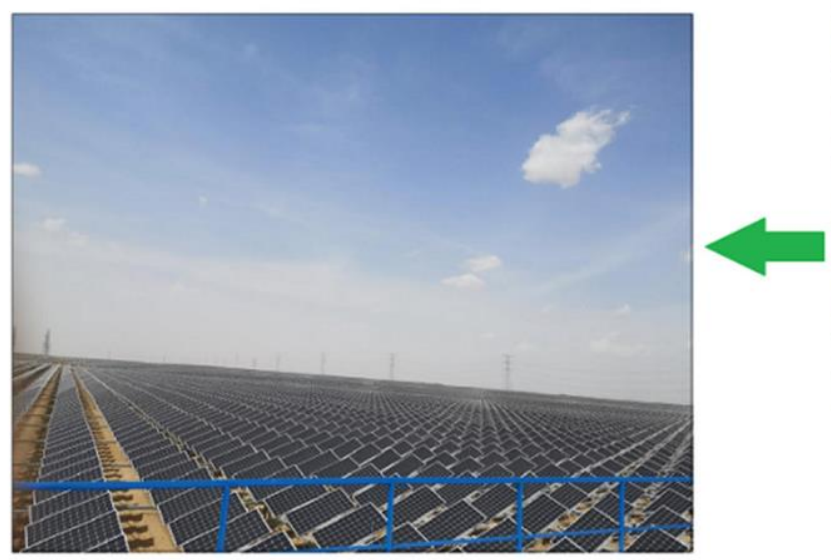

(c)

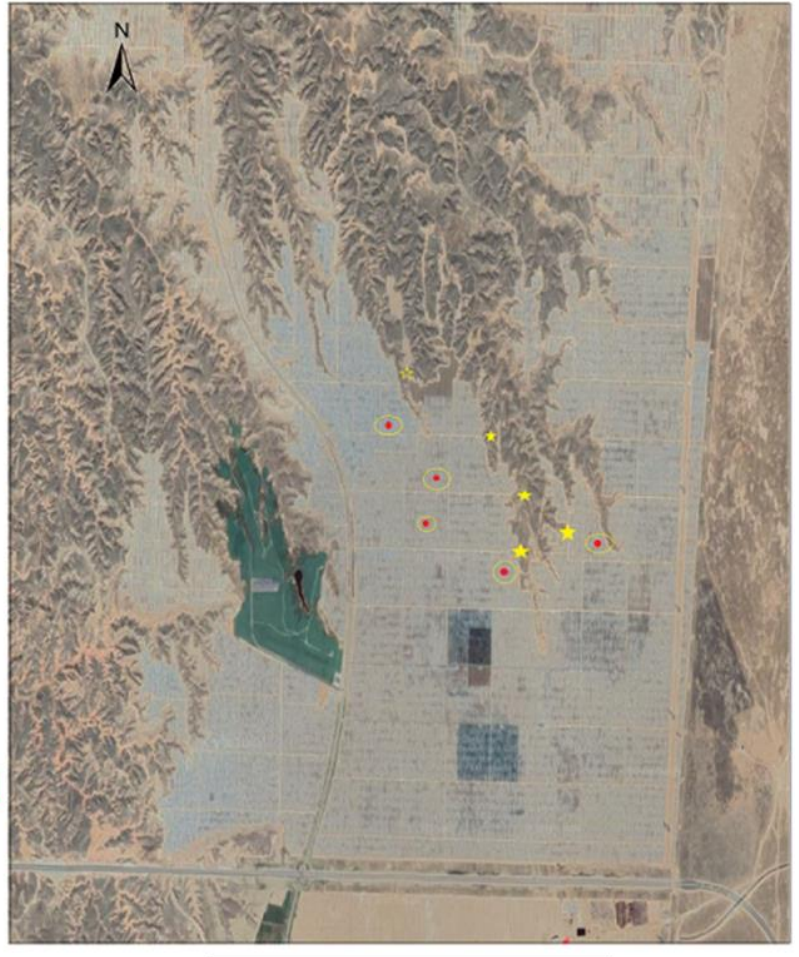

- installation units

outside station sites

(b)

Fig. 1. (a) large scale view of the solar photovoltaic panels constructed in the arid area. (b) and (c) show the vegetation conditions inside and outside the station. (d) shows the three experimental zones: the area outside the station (OS), the surface land which is vertically below the solar panels (S), and the surface ground of the station that is vertically above without solar photovoltaic panels (NS). 


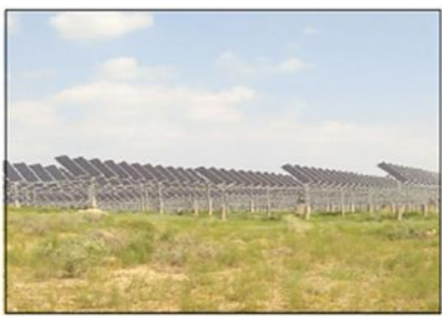

(a)

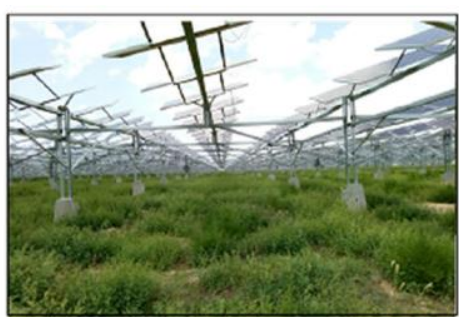

(b)

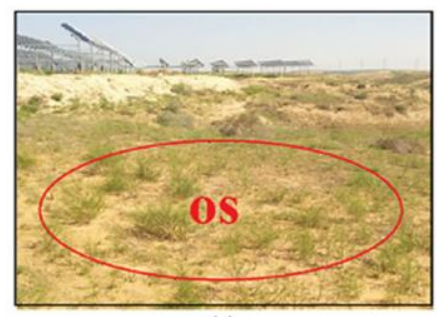

(c)

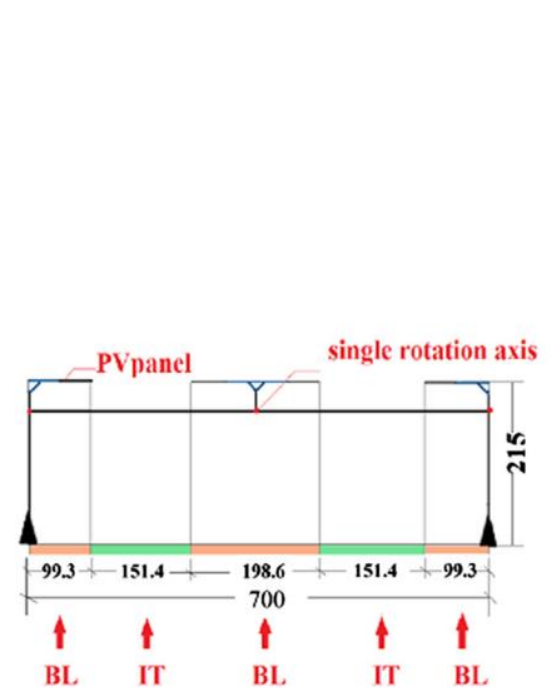

(d)

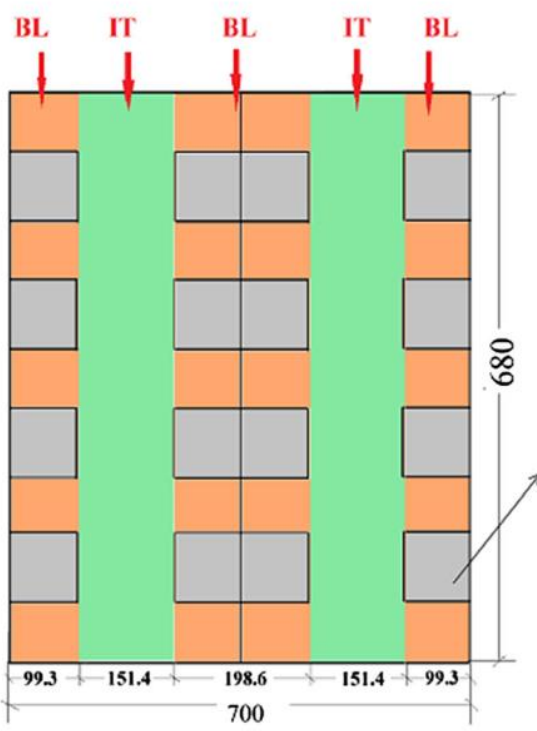

(e)

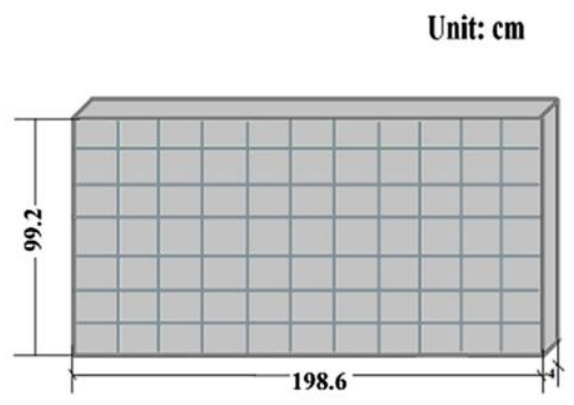

(f)

Fig. 2. Soil moisture $(0-100 \mathrm{~cm}$ in depth), soil temperature, evaporation, and photosynthetically active radiation (PAR) in the S, NS, and OS zones. Means with different letters are significantly different $(\mathrm{P}<0.05)$ between the three zones. The error bars indicate standard errors. S: land with PV panels vertically shading. NS: land without PV panels vertically shading. OS: ground outside the solar photovoltaic panels. 

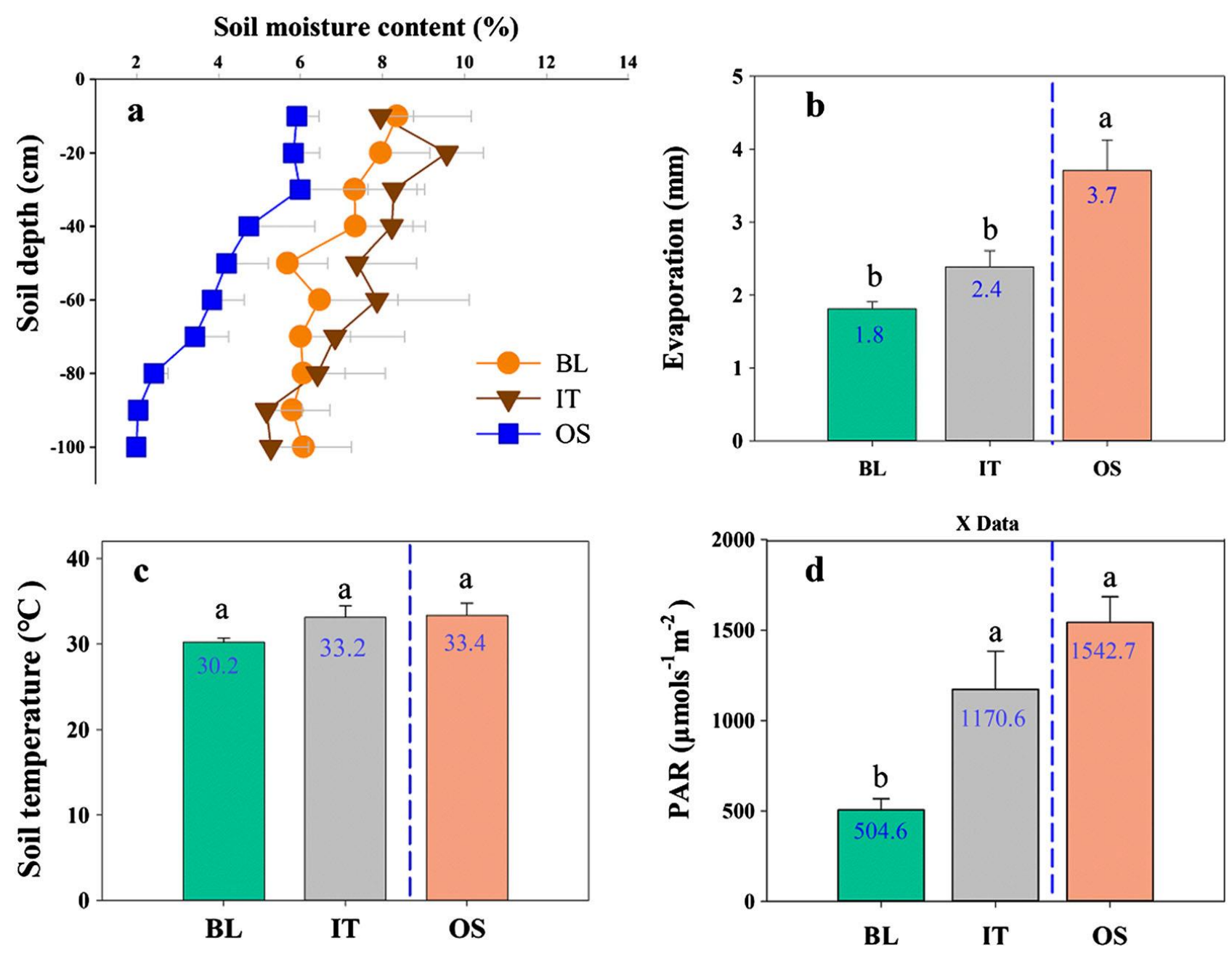

Fig. 3. (a) Monthly average temperature above and under the solar photovoltaic panels in one year. (b) Daily average temperature variation between the above and under the solar photovoltaic panels in July. The dash line is the mean temperature variation in 24 hours. 

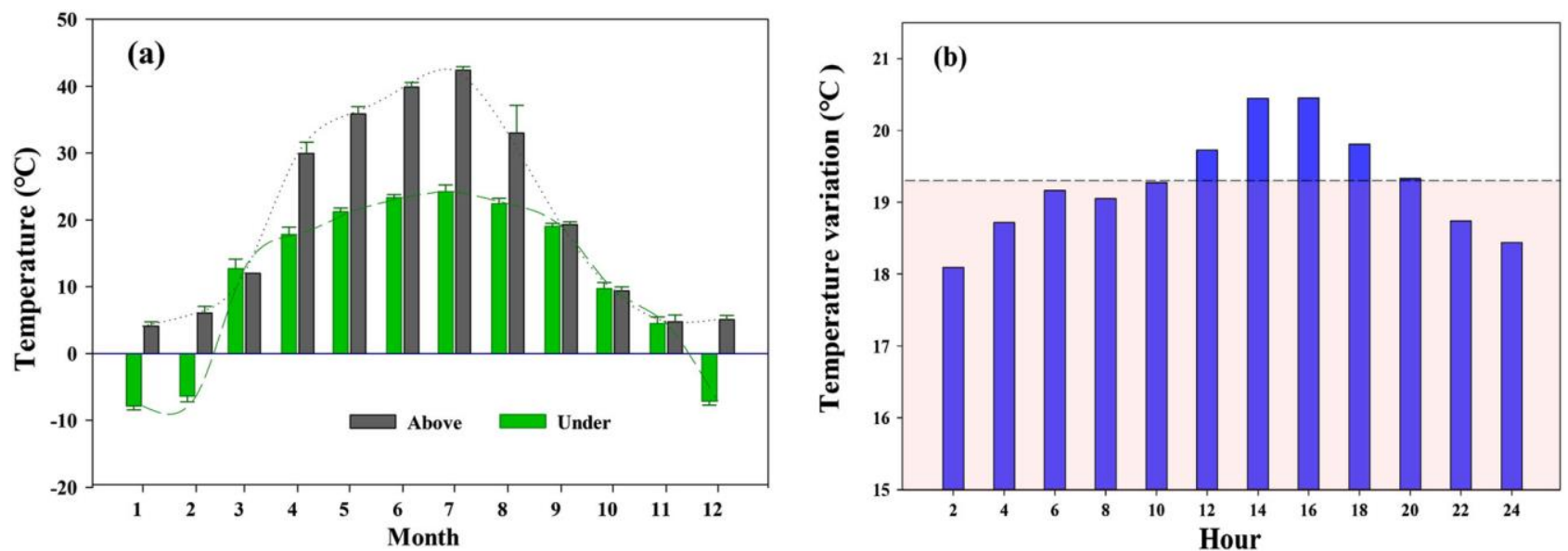

Fig. 4. (a) Monthly average temperature above and under the solar photovoltaic panels in 1 year. (b) Daily average temperature variation between above and under the solar photovoltaic panels in July. The dash line is the mean temperature variation $\left(19.27^{\circ} \mathrm{C}\right)$ in $24 \mathrm{hr}$.
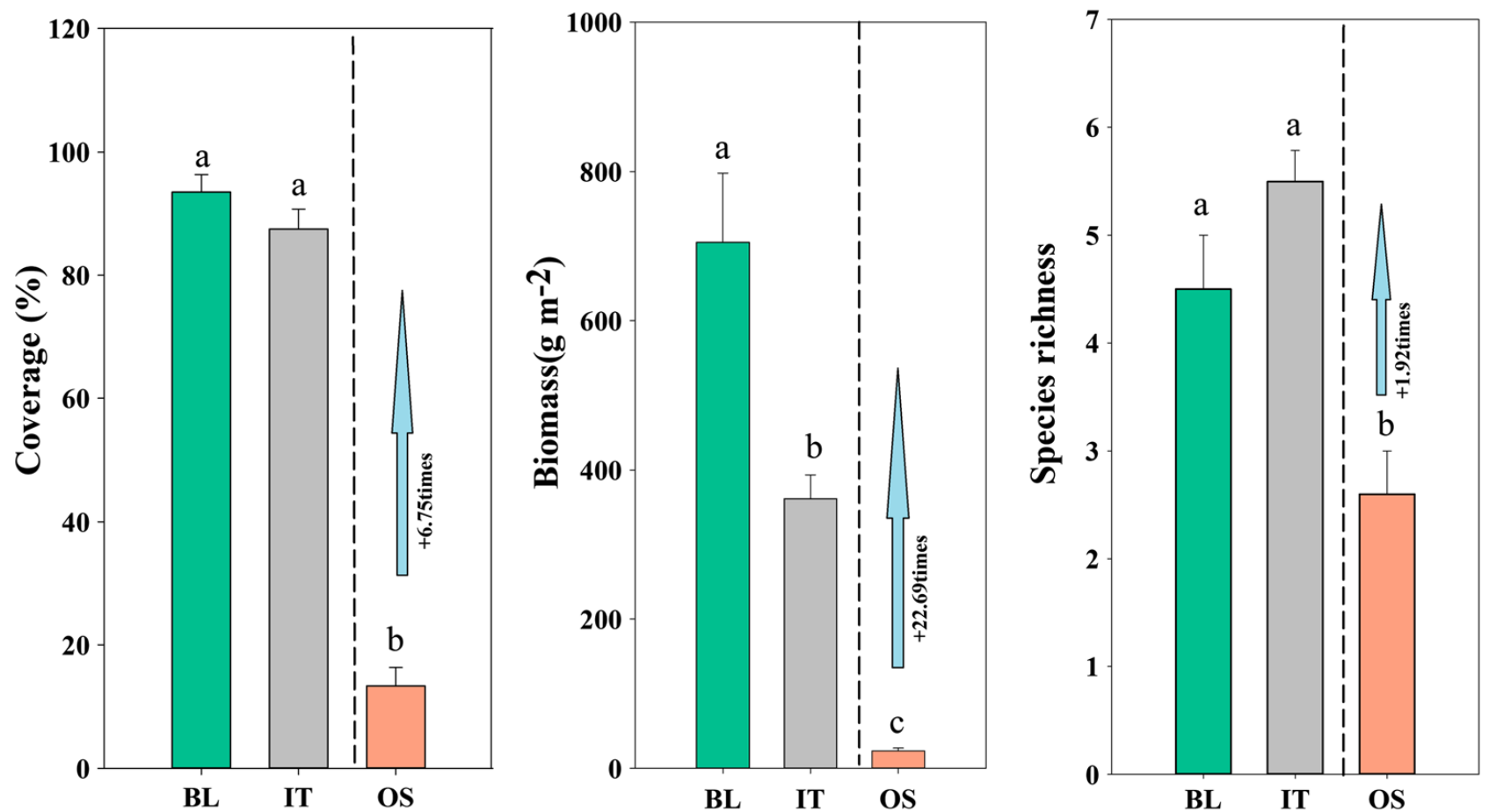

Fig. 5. Differences in vegetation coverage, biomass, and species richness between the area district vertically below the photovoltaic panel line (axis horizontality) in south-north direction (BL), area district between two photovoltaic panel lines (IT), and area district 30 m nearby solar power station (OS) zones. Different letters indicate that means are significantly different at .05 level $(\mathrm{P}<.05)$. The error bars indicate standard errors. The blue upward arrows represent the multiplicative increase in coverage, biomass, and species richness between the OS zone and average value of the BL and IT zones. 